\title{
Costs of pain in Rheumatology
}

\author{
A. Marsico ${ }^{1}$, F. Atzeni' ${ }^{2}$ A. Piroddi ${ }^{3}$, M. Cazzola 4 , S. Stisi ${ }^{5}$, P. Sarzi-Puttini ${ }^{2}$ \\ ${ }^{1}$ Rheumatologist, P.O. S.S. Annunziata, Taranto; \\ ${ }^{2}$ Rheumatology Unit, L. Sacco University Hospital, Milan; \\ ${ }^{3}$ Regional AISF Contact Person, Sardinia Region; \\ ${ }^{4}$ Rheabilitation Unit, Busto Arsizio Hospital, P.O. Saronno (VA); \\ ${ }^{5}$ Rheumatology Unit, G. Rummo, Benevento, Italy
}

\section{SUMMARY}

Chronic pain has been identified as an important issue related to various rheumatic diseases. At the time of a major government spending review, it is appropriate to discuss the pain characterising rheumatic diseases and its related costs. It is clearly essential for healthcare authorities to rationalise their policies on the basis of the increasing expectations of the users of healthcare services while simultaneously balancing their books. There are few published studies concerning the costs of pain of any kind, and the same is true of the costs of the chronic pain associated with diseases such as rheumatoid arthritis, osteoarthritis, and fibromyalgia.

Key words: Chronic pain, Direct costs, Indirect costs, Intangible costs.

Reumatismo, 2014; 66 (1): 103-107

\section{INTRODUCTION}

C hronic pain (CP) is a frequent healthcare problem worldwide and the main reason for patients seeking medical advice (1). It affects a large proportion of the inhabitants of the USA, where its prevalence is much higher than that of other conditions having a major social impact: back pain is the main cause of disability among Americans aged $<45$ years, and the latest statistics show that it affects about 26 million aged 20-64 years (2).

About 10 million people in the UK suffer from various forms of pain that have serious consequences on their quality of life and working activities. The National Rheumatoid Arthritis Society estimates that about 9.4 million working days are lost because of rheumatoid arthritis (RA), and 4.9 million because of back pain (3).

Pain in rheumatic disease (RD) (particularly chronic pain) has been identified as an important issue by the National Health Plan 2011-2013 of the Italian Ministry of Health $(4,5)$. It is considered a disease that has its own nosographic dignity. Furthermore pain measurements and further information required by medical and healthcare personnel in order to improve the patients' quality of life also involves ethical aspects that have not yet been considered (6). This is also highlighted by other important bodies, such as the International Association for the Study of Pain (IASP), the European Federation of IASP Chapters $\left(\mathrm{EFIC}^{\circledR}\right)$, the Italian Association for the Study of pain (AISD), and the Paolo Procacci Foundation (FPP).

The World Health Organization (WHO) is developing a new International Classification of Diseases (ICD-11) to be published in 2015 that will include a section entirely dedicated to pain as a nosographic element in itself and not only related to organ and system pathologies (current code 338).

In Italy, Law No. 38 entitled Provisions for access to palliative treatments and pain therapy was approved on 15 March 2010 (7), and amended Presidential Decree No. 309 of 9 October 1990 (Text for the laws regulating the use of narcotic and psychotropic substances) by further simplifying the regulations governing the prescription of drugs for the treatment of pain. Article 9 of Law No. 38/2010 states that the Ministry will provide the Regions with elements for evaluating the trends in the prescription
Corresponding author: Antonio Marsico Rheumatology Unit S.S. Annunziata Hospital Taranto, Italy E-mail: amars@tin.it 
of drugs for the treatment of pain, particularly opioid drugs.

This law is highly innovative because it guarantees the access of patients to palliative therapies and pain treatment in authorized centers, ensuring respect for their dignity, autonomy and healthcare needs; equal access to care; the quality of the care itself; and appropriate treatments for special cases.

In general, the most important features of the legislation are:

1. Pain recording from the clinical records;

2. National assistance for palliative drugs and pain treatments;

3. Simplification of the procedures to have access to the drugs used to treat pain;

4. Training for medical and healthcare personnel.

The law has also been acknowledged outside Italy, as indicated at the Third International Symposium - Societal Impact of Pain SIP 2012 and in the publication entitled Pain proposal - Improving the Current and Future Management of $C P(8,9)$.

As is happening in other economically stronger European and non-European countries, in Italy the National Health Service is going through a major economic and financial crisis that is mainly due to a reduction in funding. It was established in 1978 during a period of relative economic prosperity, inspired by the principle of solidarity, and mainly funded by the population, but it is now struggling to find sustainable means of balancing the books, reducing the national budget, and reorganizing its structure without affecting the principles that inspired its creation (10).

As in the rest of the world, RDs in Italy have a social impact that is greater than that of many other diseases because of the high costs involved, which can be divided into three main groups:

1. Direct costs, such as the cost of drugs, diagnostic examinations, care and hospitalization, and also private consultations;

2. Indirect costs, such as lost work days or unemployment due to the disease, termination of contracts given the impos- sibility of working, transport to hospital and/or visits in private practices (and the possible lost work day by anyone accompanying the patient), pushing patients to work even when their job performance is serious affected because their physical condition;

3. Intangible costs arising for instance from significant changes in the quality of life and social habits (e.g. those relating to interpersonal relationships, or severe difficulties in pursuing a hobby). The first two groups have measurable parameters, although their calculation is not easy because of the many variables involved, whereas the costs in the third group can hardly be measured at all, and remain a matter of discussion between health authorities and patients.

The negative impact of RDs on the patients' quality of life and working activity has been examined in a recent study conducted in six European countries (Belgium, Bulgaria, Ireland, Portugal, Spain and UK) (11).

\section{COSTS OF PAIN IN OSTEOARTHRITIS}

Pain is the main symptom of RDs: the pain related to osteoarthritis (OA) affects $10 \%$ of the Italian population with a prevalence of 7,129,842 cases, in particular in female $\operatorname{sex}(12)$.

Colombo et al. investigated the cost of acute and chronic pain in a prospective, observational study of the costs and the changes in the quality of life (QoL) associated with acute and chronic pain management in Italy that involved patients affected by chronic benign pain due to hip or knee OA, generalized OA, low back pain, a non-surgical hernia, slipped disc or shoulder periarthritis (13). The patients had experienced pain symptoms for at least six months before the start of the study. Various questionnaires were used to investigate the description of pain, healthcare use before and after enrolment, and the willingness to pay for therapy. The costs relating to acute pain ( $€ 57.00$ in 2004), 30 days prior to the 
clinical examination, concerned the Emergency Department accesses and self-medications, and after the clinical examination they were incurred for diagnostic examinations and drugs. As to the costs relating to chronic pain ( $€ 175.00$ in 2005), there is no significant difference in expenditure before (diagnostic examinations) and after the appointment (mainly for therapy, the rest for diagnostic examinations). Pharmacological prescriptions for acute pain included non-steroidal anti-inflammatory drugs (NSAIDs) $(61 \%)$, opioids $(40 \%)$, corticosteroids $(17 \%)$, local anesthetics $(1 \%)$, and other therapies in $(24 \%)$ of the cases; and those for chronic pain included opioids (46\%), local anesthetics (33\%), corticosteroids (29\%), NSAIDs 26\%, and other therapies (45\%). Another interesting finding was that the QoL cost of an extremely high level of pain was between $€ 79.89$ and $€ 156.05$, whereas in the case of moderate pain it was far higher, between $€ 515.21$ and $€ 843.06$.

RD-related pain is essentially chronic, and a paramount issue for public health policy makers.

\section{COSTS OF PAIN IN RHEUMATOID ARTHRITIS}

RA is a chronic disease characterized by progressive joint damage that causes disability, a worsening quality of life, and a reduced life expectancy, and affects $0.3-1.0 \%$ of the world's population (about 300,000 people in Italy); the male:female ratio is 3-4:1. The comorbidities of RA are pain, fatigue and depression. RA affects patients of any age, including people who are still working. However, the progressive disability it causes has a negative effect on working abilities and leads to lost work days and even unemployment.

According to a recent study by the Scuola Superiore Sant'Anna, the annual average cost of 253,069 patients in Italy aged $>18$ years is about $€ 3,388,593,910$, of which $€ 2,330,006,283$ are direct costs (health costs $€ 698,976,578$; non-health costs $€ 1,631,029,705)$ and $€ 1,058,587,627$ are indirect costs (14). Moreover, the total average annual cost per RA patient in Italy is $€ 13,390,69 \%$ of which ( $€ 9207$ ) is accounted for by direct costs (health costs $€ 2762$; non-health costs $€ 6445,48 \%$ of the total costs), and 31\% ( $€ 4183$ ) by indirect costs and lost productivity due to an annual average of 65 work days lost by patients and caregivers. The average annual cost of drugs per patient is $€ 2080$, leading to a total amount of $€ 526,383,520$, less than that due to lost productivity.

These findings confirm that the costs of RA (like those relating to other chronic RDs) are largely due to direct non-healthcare and indirect costs rather than direct healthcare costs. The authors concluded that, although it would increase direct healthcare costs, a greater use of biotechnological drugs could lead to a reduction in working disability and, consequently, direct non-healthcare and indirect costs.

\section{COSTS OF PAIN IN FIBROMYALGIA}

Fibromyalgia $(\mathrm{FM})$ is characterized by frequently incurable, chronic generalized pain that may be treated using analgesic drugs, NSAIDs, cyclooxygenase- 2 inhibitors (COXIBs), antidepressants, or anticonvulsants. Various studies of the costs of FM have been published (15).

Knight et al. have recently studied the costs of 442 patients (385 women) in the USA, France and Germany, and confirmed that FM has much higher indirect costs than direct costs (16).

Another recent study by Sun et al. analyzed insurance databases to find the direct medical costs of 7871 patients with FM $(89 \%$ female) who had a median age of 49 years at the start of drug treatment in 2008 (17): one group was taking duloxetine (3033), and a second pregabalin (4838). The costs in the two groups were: hospitalization \$ 2994.9 vs \$ $4949.6(\mathrm{P}<0.05)$, outpatient costs \$ 8259.6 vs $\$ 10,312.2 \quad(\mathrm{P}<0.05)$, drug costs $\$ 5214.6$ vs $\$ 5290.8(\mathrm{P}>0.05)$, and total physician costs $\$ 16,469.1$ vs $\$ 20,552.6(\mathrm{P}<0.05)$. 
A previous study by the Italian Fibromyalgia Network showed that a high degree of disability and the number of pathologies associated with FM could significantly increase the direct and indirect costs of FMrelated pain management, whereas an early diagnosis reduced the use of economic resources for drugs, medical appointments and diagnostic investigations (18).

\section{COSTS OF THE DRUGS USED FOR TREATING PAIN IN RHEUMATIC DISEASES}

The OsMeD report of AIFA (Italian Drug Agency, Agenzia Italiana del Farmaco) Use of drugs in Italy as of September 2012 refers to the use of all types of drugs in hospitals. The cost for drugs used to treat patients with conditions affecting the musculoskeletal system, which represent the eighth largest drug category in the public budget, amounted to $€ 442$ million (7.3 per capita). These costs are mainly associated with the so-called therapeutic drug assistance (6.3 per capita), whereas the purchase of drugs by the public health facilities was much less significant (1.0 per capita). With respect to the national healthcare system, the expenditure for drugs to treat musculoskeletal disorders decreased by $9.0 \%$ against 2011 . This decline is due to the combination of a reduction in consumption $(-4.3 \%)$, in prices $(-5.4 \%)$ and a positive mix effect $(+0.5 \%)$. Data shows that the purchase of these drugs by healthcare facilities is substantially stable if compared with $2011(+0.06 \%)$, while consumption by the general population is increasing $(+6.6 \%)$. The most widely used drug categories by the national healthcare service were anti-inflammatory NSAIDs and COXIBs, followed by biphosponates. In terms of expenditure, biphosponates and COXIBs are the two most relevant categories. Biphosponates are also the category with the largest impact on the budgets of healthcare facilities. No active ingredient belonging to the musculoskeletal category is among the first 30 most widely used drugs in the national healthcare budget or direct distribution, and only the zolendronic acid is in the list of hospital consumption.

Among the drugs for central nervous system disorders, the list includes selective serotonin re-uptake inhibitors, other antidepressants and natural opioid alkcaloids, which are all frequently prescribed by rheumatologist for pain treatment. In particular, they are administered to treat FM or chronic arthritis when the $\mathrm{CP}$ is associated with a suspected central sensitization. The 30 most widely used drugs also include: escitalopram $\left(14^{\text {th }}\right)$, levetiracetam $\left(19^{\text {th }}\right)$ pregabalin $\left(24^{\text {th }}\right)$, acetylsalicylic acid $\left(25^{\text {th }}\right)$ and duloxetine $\left(26^{\text {th }}\right)$.

A recent Federfarma publication (April 2013) on drug consumption in Italy reported that musculoskeletal agents ranked $7^{\text {th }}$ in terms of incidence on the healthcare budget in $2012(19,20)$. The group of anti-neoplastic and immune-modulating drugs includes biotechnological drugs, but no mention is made of opioids or analgesic agents. Rheumatologic drugs were not among the most prescribed in 2012 nor among the first ten with the highest turnover in Italy. Vitamin $\mathrm{D}$ is included, but it is also prescribed by general practitioners and other specialists. According to a Farmindustria report, sales of musculoskeletal drugs in Italy in 2011 accounted for $5.9 \%$ of total expenditure, which is less if compared with $24.9 \%$ for cardiovascular drugs, $15.1 \%$ for central nervous system drugs, and $14.7 \%$ for gastrointestinal drugs (21).

The publication Pain proposal - Improving the Current and Future Management of Chronic Pain describes the results of a survey conducted in 15 European countries (including Italy) on the social impact of chronic pain. It addresses the following topics: Time to diagnosis in Europe (from not been diagnosed to 10 years or more), Average time to diagnosis (years), Time from diagnosis to adequate pain management, Percentage still not diagnosed or not adequately managed, impact of pain on daily activities, and Average number of healthcare professional visits in the prior year. It concludes that a late diagnosis and an inadequate management of $\mathrm{CP}$ increase 
global costs (visits, diagnostic examinations, drugs, etc.), however Italy seems to be in a good position in terms of time to diagnosis.

Indirect costs also include costs due to side effects. An observational study presented by J. Goldstein in San Diego on the occasion of the Digestive Disease Week made use of an administrative database of 15 million people, $97 \%$ of whom were covered by commercial insurance policies. The analysis involved 1800 patients (2/3 female) with an average of 60 years, who were prescribed NSAIDs for 90 days because of OA. During the following 12 months, anemic patients were more likely to use healthcare resources (drugs, visits and diagnostic investigations) with an average cost of $\$ 42,368$ against an average of $\$ 22,583$ in a control group of patients who used NSAIDs but did not experience any significant change in hemoglobin levels $(\mathrm{P}<0.0001)(22)$.

\section{ACKNOWLEDGEMENTS}

The authors would like to thank Paolo and Matteo for their support.

\section{REFERENCES}

1. Fanelli G, Ventrigli G. Il dolore cronico in medicina generale. 2010: Available from: http:// www.salute.gov.it/

2. Sarzi-Puttini P, Vellucci R, Zuccaro SM, Cherubino P, Labianca R, Fornasari D. The appropriate treatment of chronic pain. Clin Drug Investig. 2012; 32: 21-33.

3. The American Academy of Pain Medicine (AAPM). Incidence of pain, as compared to major conditions. In: AAPM facts and figures on pain. Available from: http://www. painmed.org/patientcenter/facts_on_pain. aspx\#incidence

4. The British Pain Society. FAQs. Available from: http://www.britishpainsociety.org/media_faq.htm

5. Coaccioli S, Varrassi G, Marinangeli F, Aurilio C, Finco G, Gatti A, Geppetti Pet al. An ethics code for pain. Eur J Pain. 2012; 16: 1081-3.

6. Croft P, Blyth FM, van der Windt D, eds. Chronic pain epidemiology: from aetiology to public health. Oxford: Oxford Univ Press; 2010.

7. Italian Regulation. Legge 15 marzo 2010, n. 38. Disposizioni per garantire l'accesso alle cure palliative e alla terapia del dolore. In: G.U. no. 65, 19/03/2010. Available from: http:// www.parlamento.it/parlam/leggi/100381.htm

8. The Societal Impact of Pain (SIP). A multistakeholder platform in Europe. Available from: http://www.sip-platform.eu

9. Arthritis Care. Pain proposal improving the current and future management of chronic pain .2010. Available from: http://www.arthritiscare.org.uk/

10. Centre for Economic and International Studies (CEIS). Il futuro del Servizio Sanitario in Europa e in Italia. I report di Economist e CEIS Tor Vergata. Il Sole 24 Ore - Sanità. 2012; 40: 1-45. Available from: http://www.jlive.it/ SurveyScenari/img/futuro_servizio_sanitario_CEIS.pdf

11. Zheltoukhova K. Musculoskeletal disorders and work. Results of a survey of individuals living with musculoskeletal disorders in six European countries. London: The Work Foundation; 2013. Available from: http://www.fitforworkeurope.eu/FFW_Patient_Survey_FINAL_2013.pdf

12. ISTAT. Il benessere equo e sostenibile.2013. Available from: http://demo.istat.it/bilmens2013gen/index.html

13. Colombo GL, Caruggi M, Serra G, Vinci M. Management of acute pain in Italy. Economic aspects and quality of life. Recenti Prog Med. 2005; 96: 7-15.

14. Scuola Superiore Sant'Anna. Studio sui costi economici e sociali dell'artrite reumatoide. Turchetti G. Available from: http://www.sssup.it/

15. Leardini G. I costi della sindrome fibromialgica. Fibromialgia. Atti convegno 2009 Bologna. pp 271-275.

16. Knight T, Schaefer C, Chandran A, Zlateva G, Winkelmann A, Perrot S. Health-resource use and costs associated with fibromyalgia in France, Germany, and the United States. Clinicoecon Outcomes Res. 2013; 5: 171-80.

17. Sun P, Peng X, Sun S, Novick D, Faries DE, Andrews JS, et al. Direct medical costs and medication compliance among fibromyalgia patients: duloxetine initiators vs. pregabalin initiators. Pain Pract. 2014; 14: 22-31.

18. Altomonte L, Atzeni F, Leardini G, Marsico A, Gorla R, Casale R. Fibromyalgia syndrome: preventive, social and economic aspects. Reumatismo. 2008; 60: 70-8.

19. Pharmastar. Consumo dei farmaci. Comunicato stampa. Aprile 2013. Available from: http:// www.pharmastar.it

20. Federfarma.Consumo farmaci. Aprile 2013. Available from: http://www.federfarma.it

21. Farmindustria.Report consumo dei farmaci. Available from: http://www.farmindustria.it

22. Goldstein J. Healthcare resource utilization and economic impact of $\mathrm{a} \geq 2 \mathrm{~g} / \mathrm{dL}$ decrease in hemoglobin after NSAID treatment in osteoarthritis patients. DDW 2012; abstract 481. 